\title{
EFFECT OF BENEFICIATION ON THE CHARACTERIZATION OF GETSO KAOLIN
}

\author{
Nurudeen SALAHUDEEN ${ }^{1 *}$, Ahmad A. MUKHTAR ${ }^{2}$ \\ ${ }^{1}$ Department of Chemical and Petroleum Engineering, Bayero University, Kano, Nigeria, nsalahudeen.cpe@buk.edu.ng \\ ${ }^{2}$ Department of Chemical and Petroleum Engineering, Bayero University, Kano, Nigeria
}

DOI: $10.2478 / \mathrm{minrv}-2021-0036$

Keywords: Getso kaolin; Clay; XRD; pH; Specific gravity

Abstract: In their raw forms, clay minerals are found with a number of inherent impurities which make them unsuitable for most industrial applications. In order to overcome this problem and add value to clay minerals, beneficiation process is an indispensable solution. This study investigates effect of wet beneficiation process on the characteristics of a local clay mined from Getso village of Kano State, Nigeria. Mineralogical characterization of the clay was carried out using X-ray diffraction (XRD) analyzer. Chemical characterization of the clay was carried out using X-ray fluorescence analyzer. Physicochemical characterization of the clay was carried out using $\mathrm{pH}$ meter and density analysis conducted using density bottle. XRD analysis of Getso clay showed that the raw clay had 8 wt\% kaolinite and $51 \%$ quartz. Wet beneficiation resulted into 53\% improvement of the kaolinite content and $47 \%$ reduction of quartz impurity. The XRF analysis has shown that silica-alumina ratio of the raw Getso clay was 1.55 and this reduced to 1.49 after beneficiation. The physicochemical characterization of the clay has shown that Getso clay is neutral, the raw clay and beneficiated clay had average $\mathrm{pH}$ values of 7.5 and 7.3, respectively. Specific gravity values of the raw and beneficiated clay were 2.24 and 2.04, respectively. The beneficiation process had been effective as substantial increase in kaolinte content was observed and a reasonable decrese in the impurity contents was observed from the raw to the beneficiated clay. The Garnet content was completely reduced to zero while quartz, clinochlore and orthoclase were reduced by $24 \%, 9 \%$ and $13 \%$ respectively. The clay obtained after the beneficiation be serve as good raw material for production of whitewares, high grade ceramics in synthesis of zeolitic materials.

\section{Introduction}

Clay is a layered structures of fined-grained minerals which occur naturally [1]. Clay material has particle size of about $1 \mu \mathrm{m}$ [2]. Clay is a fine textured material produced by the weathering process of granite and feldspathic rocks $[3,4]$. The small particle size and huge surface to volume ratio properties of clay impact on them excellent properties such as high cation exchange capacities, catalytic properties, and plastic behavior needed for their industrial applications [5]. Clay is formed in various classifications each having a distinctive mineral and crystal structural pattern. Each classification of clay possesses a set of unique structural and physical properties which differentiate it from other members of the clay family. They various classifications include; kaolinite, montmorillonite, illite, vermiculite and chlorite. Clay is known for its long use by human for production of ceramic materials as far back as the early stage of human civilization [6]. Modern applications of clay include ceramics application in producing products such as whitewares, high temperature porcelains, sanitary ware and electrical insulators [7].

Kaolinite has been the major class of clay used in the production of ceramic and whiteware porcelain. Kaolin also called china clay is a high demanded raw material used in production of variety of industrial products which include housewares, building materials ceramics, porcelain, paint, paper, white incandescent light bulbs, skincare products etc [8]. In addition, kaolin I also applied in pharmaceutical, and composite

\footnotetext{
* Corresponding author: Nurudeen Salahudeen, Assoc. Prof., Bayero University, Kano, Nigeria, (PMB 3011, Gwarzo

Road Kano, Nigeria, nsalahudeen.cpe@buk.edu.ng)
} 
materials industries [9]. Kaolinite group is chemically represented as $\mathrm{Al}_{2} \mathrm{Si}_{2} \mathrm{O}_{5}(\mathrm{OH})_{4}$. Structurally it possesses one silica and one alumina unit molecules stacked in alternating fashion known as 1:1 lattice type [10]. The choice of kaolin for industrial applications is largely dependent on its purity [11]. Nigeria has been reported to have huge reserves of kaolin mineral which can be harnessed for great economic benefits [12].

This work is aimed at investigating effect of beneficiation on the characteristics of Getso kaolin with the objective of improving the suitability of the clay for industrial applications.

\section{Materials and methods}

\subsection{Materials and Equipment}

The raw clay was mined from Getso village in Gwarzo Local Government Area, Kano State, Nigeria. The deposit's GPS coordinate was $11^{\circ} 53^{\prime} \mathrm{N}$ north and longitude E $7^{\circ} 58^{\prime} \mathrm{E}$. Equipment used include, pH Meter (Model; 3510 pH meter), XRD machine (Model; BRUKER S2 RANGER). Apparatus used include weighting balance, glassware and density bottle.

\subsection{Methods}

\subsubsection{Beneficiation}

Wet beneficiation of Getso clay was carried out as presented in our previous work [13]. The raw clay was crushed and ground. The ground clay was soaked overnight in water in a predetermined ratio of $0.1 \mathrm{~g} / \mathrm{L}$. The clay-water mixture was plunged by stirred for $3 \mathrm{~h}$ then left to settle. After letting, the supernatant water was decanted and the sedimented clay was sieved using mesh size of \#200. The fine clay filtrate known as the beneficiated clay was dewatered, dried, ground and weighted. The residue impurity was collected, dried and weighted.

\subsubsection{XRD analysis}

The clay sample was pulverized, homogenized and a wafer of the clay was made. The clay wafer was mounted on the sample stage in the XRD cabinet. The sample was analyzed using the reflection-transmission spinner stage at Theta-Theta settings. XRD scan was carried out at $2 \theta$ range of $4^{\circ}-75^{\circ}$ using $2 \theta$ step of $0.026261^{\circ}$ at $8.67 \mathrm{~s} / \mathrm{step}$. Tube current was set at $40 \mathrm{~mA}$ and the tension was $45 \mathrm{VA}$.

\subsubsection{X-ray fluorescence analysis}

The clay sample was pulverized, homogenized and a wafer of the clay was made. The clay wafer was mounted on the sample stage in the XRF cabinet for the determination of the metallic oxides compositions.

\subsubsection{Physicochemical analysis}

Specific gravity analysis was carried out using density bottle. Using a weighting balance, weight of empty density bottle was measured as $\mathrm{W}_{1}$. Weight of the bottle plus clay filled to the bottle mark was measured as $\mathrm{W}_{2}$. Weight of the bottle plus clay plus water was measured as $\mathrm{W}_{3}$. Weight of the bottle plus only water filled to the bottle mark was measured as $\mathrm{W}_{4}$. The specific gravity of the clay sample was determined using Equation (1) $[14]$.

$$
\text { Specific gravity }=\frac{\left(W_{2}-W_{1}\right)}{\left(W_{4}-W_{1}\right)-\left(W_{3}-W_{2}\right)}
$$

$\mathrm{pH}$ analysis was carried out by preparing different samples of clay-water mixtures using $10 \mathrm{~g}$ constant weight of clay and varying weight of water so as to make 1:1, 1:2,1:3 and 1:4; wt $\%$-wt $\%$ of clay-to-water in each case, respectively. At each experimental run three readings of $\mathrm{pH}$ value of the mixture were taken and the average reading was considered for the $\mathrm{pH}$ analysis result. 


\section{Results and discussion}

\subsection{Beneficiation}

Starting with $1500 \mathrm{~g}$ raw clay sample for the beneficiation, $1027 \mathrm{~g}$ was recovered as the beneficiated clay, implying $68.46 \%$ recovery for the beneficiation process. The amount of residue obtained was $327 \mathrm{~g}$, implying $21.8 \%$ removal of impurity. The remaining $9.7 \%$ was loss likely due to soluble impurities, suspended impurities such as organic matters and debris in the raw clay. The residue was the dense mineral impurity which was likely to be quartz.

\subsection{XRD Analysis}

Figure 1 shows the qualitative XRD patterns of the raw Getso clay. It could be observed that the mineral phases present in the raw clay are kaolinite, quartz, orthoclase, clinochlore and garnet. Kaolinite peak which could be observed as the dominant mineral phase was identified at $2 \theta$ values of $12.4^{0}, 20.5^{\circ}, 24.9^{\circ}$ and $35.1^{\circ}$ each corresponding to intensity readings of $1500,500,1800$ and 400 counts, respectively. The quartz phase present were identified at $2 \theta$ values of $26.6^{\circ}$ and $38.5^{\circ}$ which correspond to intensity readings of 9200 and 250 counts, respectively. Other impurities identified include clinochlore at $2 \theta$ values of $13^{\circ}$ and $25^{\circ}$; orthoclase at $2 \theta$ values of $36^{\circ}$ and $52^{\circ}$ and garnet at $2 \theta$ values of $39^{\circ}$ and $56^{\circ}$.

Figure 2 shows the quantitative XRD analysis of raw Getso clay. It could be observed that the kaolinite content of the clay was $8 \%$ and the quartz composition was $51 \%$. The of other impurities present were $18 \%$, $16 \%$ and $7 \%$ for the orthoclase, clinochlore and garnet, respectively.

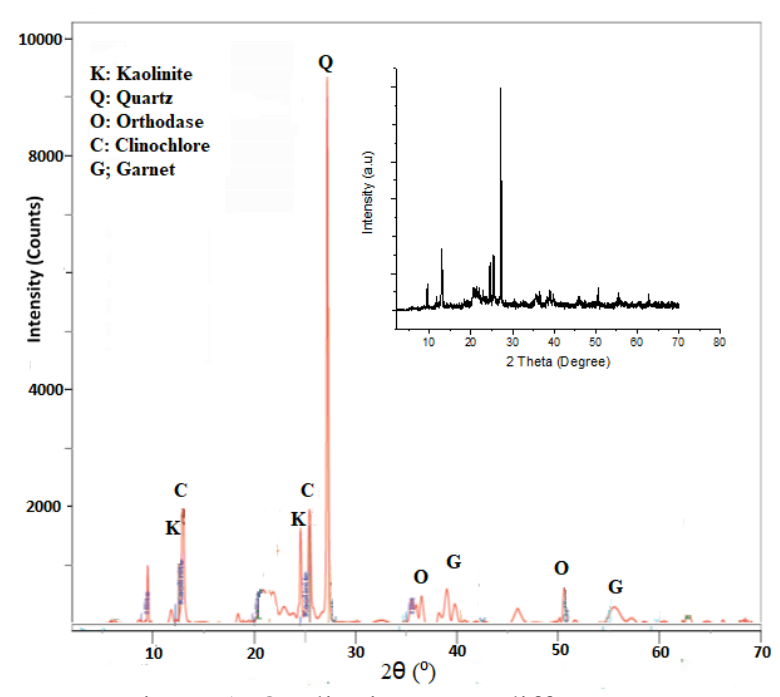

Figure 1. Qualitative XRD diffractogram of raw Getso clay

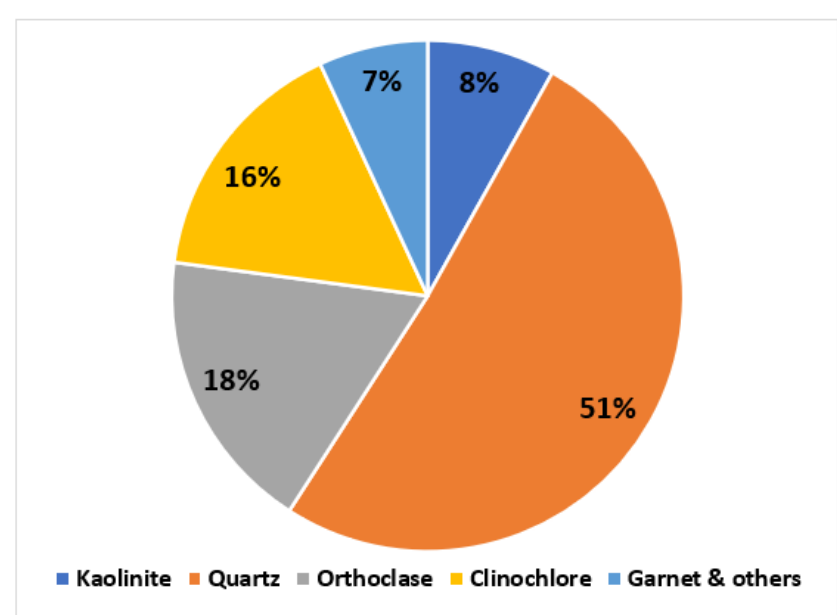

Figure 2. Quantitative XRD of raw Getso clay

Figure 3 shows the qualitative XRD patterns of the beneficiated Getso clay. The peaks of kaolinite at $2 \theta$ values of $12.4^{\circ}, 20.5^{\circ}, 24.9^{\circ}$ and $35.1^{\circ}$ became more prominent in the beneficiated clay. The corresponding intensity readings were $6200,700,4800$ and 800 counts, for the $2 \theta$ values of $12.4^{\circ}, 20.5^{\circ}, 24.9^{\circ}$ and $35.1^{\circ}$, respectively. The intensity of quartz at $2 \theta$ values of $26.6^{\circ}$ had reduced drastically from the initial value of 9200 counts in the raw clay to 1500 counts in the beneficiated clay. The peaks for the other impurities could be observed to have reduced similarly.

Figure 4 shows the quantitative XRD analysis of the beneficiated Getso clay. It could be observed that the kaolinite content of the beneficiated clay had improved immensely from the initial value of $8 \%$ in the raw clay to $61 \%$ in the beneficiated clay. The quartz composition had reduced immensely from the initial value of $51 \%$ in the raw clay to $27 \%$ in the beneficiated clay. Garnet was completely absent in the beneficiated clay while orthoclase and clinochlor had each reduced by $5 \%$ and $7 \%$ respectively. 


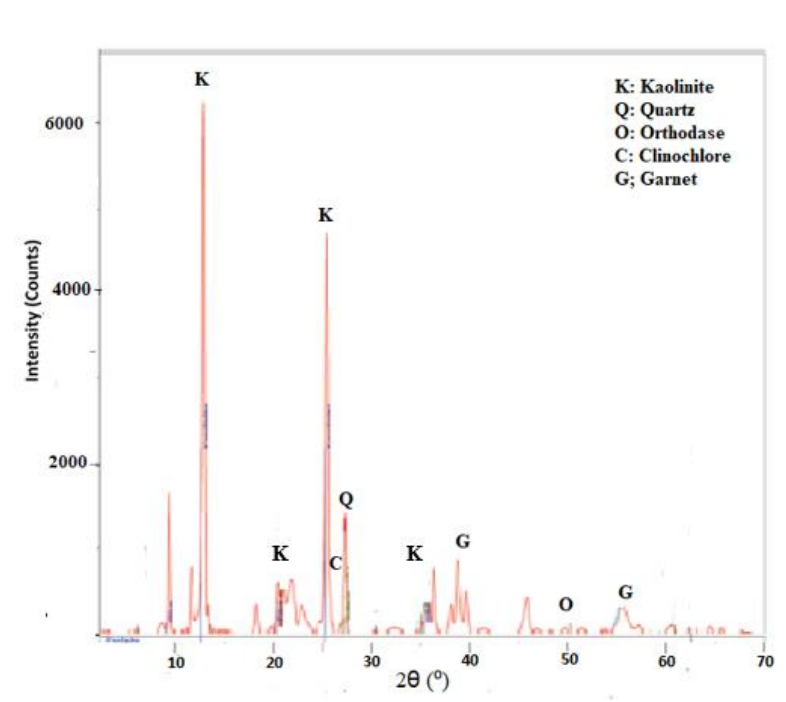

Figure 3. Qualitative XRD diffractogram of Beneficiated Getso clay pp. $72-77$

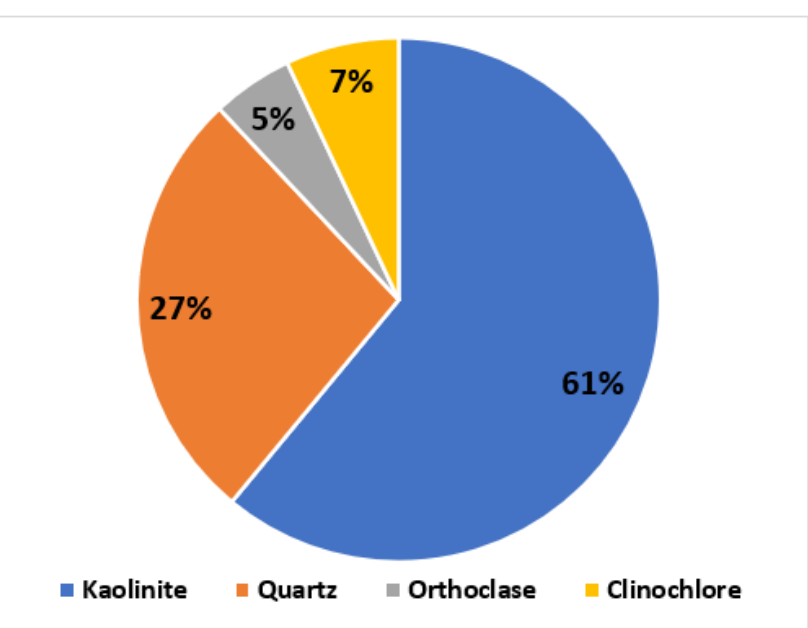

Figure 4. Quantitative XRD of Beneficiated Getso clay

Table 1 presents a tabular analysis of the XRD results of Getso clay before and after beneficiation. It could be observed that the major kaolinite peaks at $2 \theta$ values of $12.4^{\circ}$ and $24.9^{\circ}$ had intensities of 1500 and 1800 counts, respectively in the raw clay. These kaolinite intensities increased by $313 \%$ and $166 \%$, respectively after the beneficiation process. Quantitatively this translated into 53\% increase in the kaolinite content. The beneficiation process had been effective as substantial decrese in the impurity content could be observed from the raw to the beneficiated clay. The Garnet content was completely reduced to zero while quartz, clinochlore and orthoclase were reduced by $24 \%, 9 \%$ and $13 \%$ respectively.

Table 1. Analysis of the XRD results for the raw and beneficiated Getso clay

\begin{tabular}{|l|c|c|c|c|c|}
\hline Constituent & \multirow{2}{*}{$\begin{array}{c}\text { XRD Major } \\
\text { Mineral }\end{array}$} & \multicolumn{2}{|c|}{ Intensity (Count) } & \multicolumn{2}{c|}{ Quantitative XRD (\%) } \\
\cline { 3 - 6 } & Peak ( $)$ & Raw Clay & Beneficiated Clay & Raw Clay & Beneficiated Clay \\
\hline kaolinite & $12.4 \& 24.9$ & $1500 \& 1800$ & $6200 \& 4800$ & 8 & 61 \\
\hline Quartz & 26.6 & 9200 & 1500 & 51 & 27 \\
\hline Clinochlore & 13 & 2000 & 750 & 16 & 7 \\
\hline Orthoclase & 52 & 650 & 50 & 18 & 5 \\
\hline Garnet & 39 & 650 & 200 & 7 & 0 \\
\hline
\end{tabular}

\subsection{Chemical Characterization}

The XRF chemical compositions of the raw and beneficiated Getso clay are as presented in Table 2. The silica-alumina ratio of the raw clay which was 1.55 reduced to 1.49 after the beneficiation process. This was likely due to the removal of silica components such as quartz as already determined in the beneficiation and XRD results. A complete absence of $\mathrm{MgO}$ was observed after beneficiation. This was likely due to complete removal of magnesium-containing impurities during the beneficiation process. Other metallic oxides which reduced as a result of the beneficiation were $\mathrm{P}_{2} \mathrm{O}_{5}$ and $\mathrm{MnO}$.

Table 2. X-ray fluorescence results of Getso clay

\begin{tabular}{|l|c|c|c|c|c|c|c|c|c|}
\hline \multicolumn{1}{|c|}{ Oxide (wt\%) } & $\mathbf{S i O}_{\mathbf{2}}$ & $\mathbf{A l}_{\mathbf{2}} \mathbf{O}_{\mathbf{3}}$ & $\mathbf{F e}_{\mathbf{2}} \mathbf{O}_{\mathbf{3}}$ & $\mathbf{K}_{\mathbf{2}} \mathbf{O}$ & $\mathbf{P}_{\mathbf{2}} \mathbf{O}_{\mathbf{5}}$ & $\mathbf{M g O}$ & $\mathbf{M n O}$ & $\mathbf{C a O}$ & $\mathbf{T i O}_{\mathbf{2}}$ \\
\hline Raw & 55.68 & 35.95 & 2.48 & 1.42 & 0.83 & 0.59 & 0.31 & 0.3 & 0.23 \\
\hline Beneficiated & 55.51 & 37.30 & 3.13 & 1.47 & 0.59 & 0.0 & 0.20 & 0.43 & 0.30 \\
\hline
\end{tabular}

\subsection{Physicochemical Characterization}

\subsection{1. pH analysis}

The $\mathrm{pH}$ analysis results of the various clay-water mixture are as presented in Table 3. The raw Getso clay had an average $\mathrm{pH}$ value of 7.5. Beneficiation of the clay reduced the $\mathrm{pH}$ value marginally as the beneficiated clay had $\mathrm{pH}$ value of 7.3. It could be inferred that either in the raw or beneficiated form Getso clay is neutral. 
The neutrality was enhanced by the beneficiation process as the $\mathrm{pH}$ value of the clay was closer to 7.0 absolute neutral point after beneficiation.

Table 3. pH analysis of Getso clay

\begin{tabular}{|l|c|c|c|c|c|}
\hline \multicolumn{1}{|c|}{ Clay to water ratio } & $\mathbf{1 : 1}$ & $\mathbf{1 : 2}$ & $\mathbf{1 : 3}$ & $\mathbf{1 : 4}$ & Average pH of Sample \\
\hline pH of raw clay & 7.7 & 7.5 & 7.4 & 7.4 & 7.5 \\
\hline pH of beneficiated clay & 7.2 & 7.3 & 7.3 & 7.4 & 7.3 \\
\hline
\end{tabular}

\subsubsection{Specific gravity}

Table 4 presents the specific gravity analysis of Alkalari clay. Applying Equation (1) the specific gravity of the raw clay was determined as 2.24 . After beneficiation the specific gravity of the clay reduced by $9 \%$. This was likely due to the effect of quartz removal as quartz is the densest constituent of a clay [13]. This result further validates results of the beneficiation and XRD which earlier suggested removal of quartz during beneficiation.

Table 4. Specific gravity analysis of Alkalari clay

\begin{tabular}{|l|c|c|}
\hline \multicolumn{1}{|c|}{ Weight (g) } & Raw Clay & Beneficiated Clay \\
\hline $\mathrm{W}_{1}$ & 29.3 & 29.3 \\
\hline $\mathrm{W}_{2}$ & 72.4 & 80.3 \\
\hline $\mathrm{W}_{3}$ & 102.2 & 104.4 \\
\hline $\mathrm{W}_{4}$ & 78.3 & 78.3 \\
\hline Specific gravity & 2.24 & 2.04 \\
\hline
\end{tabular}

\section{Conclusion}

Mineralogical characterization of raw Getso clay has revealed that the clay was a kaolin clay having high content of mineral impurities such as quartz, orthoclase, clinochlore and garnet. The raw clay contained only $8 \mathrm{wt} \%$ kaolinite and 51\% quartz. However, the beneficiation process was quite effective as it improved the kaolinite content by $660 \%$ while the quartz impurity was decreased by $47 \%$. The chemical characterization has shown that silica-alumina ratio of the raw Getso clay was 1.55 and this reduced to 1.49 after beneficiation due to reduction in quartz and other dense impurities. The beneficiation process resulted into complete removal of $\mathrm{MgO}$ and reduction of $\mathrm{P}_{2} \mathrm{O}_{5}$ and $\mathrm{MnO}$ impurities. The physicochemical characterization has shown that Getso clay is neutral having average $\mathrm{pH}$ values of 7.5 and 7.3 for the raw and beneficiated clay, respectively. The specific gravity of the raw Getso clay which was 2.24 reduced by $9 \%$ after beneficiation. It could be referred that good commercial grade china clay could be produced from Getso clay if it undergoes wet beneficiation process. The china clay produced could be serve as an excellent raw material for production of whitewares such as tiles, high grade ceramics and even used in synthesis of high-tech materials such as zeolite catalysts [15].

\section{References}

[1] Zhang Z., Wang H., Yao X., Zhu Y., 2012

Effects of halloysite in kaolin on the formation and properties of geopolymers. Cement and Concrete Composites, Vol. 34, pp. 709-715.

[2] Fabbri B., Gualtieri S., Leonardi C., 2013

Modifications induced by the thermal treatment of kaolin and determination of reactivity of metakaolin. Applied Clay Science, Vol. pp. 73, 2-10.

[3] Hassan, M.D., 2014

Geochemistry and Origin of the Cretaceous Sedimentary Kaolin Deposits, Red Sea. Egypt. Geochemistry, 74, pp. 195203.

[4] Huggett, J.M., 2015

Clay Minerals, Reference Module in Earth Systems and Environmental Sciences, Elsevier. DOI: 10.1016/B978-0-12409548-9.09519-1 
[5] Rashad A.M., 2013

Metakaolin as cementitious material: history, sources, production and composition - A comprehensive overview. Construction and Building Materials, Vol. 41, pp. 303-318.

[6] Bergaya F., Lagaly G., 2013

Handbook of Clay Science, 2nd Edition, Elsevier Ltd., pp. 118 -1295.

[7] Reed, J.S., 2001

Introduction to the Principles of Ceramic Processing New York: John Wiley, pp. 20-23.

[8] Angela M., Moses E., Dumebi O., Simisola T., Felix I., Francis E., Emeka O., 2020

Parametric investigation of indigenous Nigeria mineral clay (Kaolin and Bentonite) as a filler in the Fluid Catalytic Cracking Unit (FCCU) of a petroleum refinery. Alexandria Engineering Journal, Vol. 59, pp. 5207-5217.

[9] Murray H.H., 2006

Applied Clay Mineralogy: Ocurrences, Processing and Application of Kaolins, Bentonites, Palygorskite-Sepiolite, and Common Clays: Development in Clay Science. 2nd Edition, Elsevier, Amsterdam.

[10] Ya W.D., Fang L.T., Yan W., Xiaodong W., Guannan L., Long Z., 2021

Facile preparation of kaolin supported silver nanparticles mediated by Thymbra spicata extract and investigation of the anti-human lung cancer properties. Journal of Saudi Chemical Society, Vol. 25, pp. 101303.

[11] Ayman A., Faris M., Ruba A., 2020

Synthesis of Kaolin-based alkali-activated cement: carbon footprint, cost and energy assessment. Journal of Materials Research and Technology, Vol. 9, No.4, pp. 8367-8378.

[12] Omowumil O.J., 2000

Characterization of some Nigerian Clay as Refractory Materials for Furnace Lining. Nigerian Journal of Engineering Management, Vol. 2, No. 3, pp. 1-4.

[13] Salahudeen, N., 2018

Metakaolinization effect on thermal and physiochemical properties of kankara kaolin. Int j Appl Sci Technol, Vol. 11, No. 2, pp. 127-135.

[14] Salahudeen N., Mohammed U., Yahya M.N., 2021

Chemical, Morphological Characterizations of RiriwaiBiotite and Determination of Yield Point of its WeightingAgent Application in Drilling Mud. Nigerian Journal of Technology, Vol. 40, No. 20, pp. 269-274.

[15] Salih K.K., Burcu A., 2020

One pot fusion route for the synthesis of zeolite 4A using kaolin. Advanced Powder Technology, Vol. 10, pp. 43364343.

This article is an open access article distributed under the Creative Commons BY SA 4.0 license. Authors retain all copyrights and agree to the terms of the above-mentioned CC BY SA 4.0 license. 